\title{
Estimation of hydrological response of a small Mediterranean watershed to fire by data analysis and a modelling approach
}

\author{
LYUDMILA LEBEDEVA ${ }^{1,4}$, OLGA SEMENOVA ${ }^{2,3,4}$ \& NATHALIE FOLTON ${ }^{5}$ \\ 1 Nansen Environmental and Remote Sensing Centre, 14 Line VO, 7, 199034 St. Petersburg, Russia \\ lyudmilaslebedeva@gmail.com \\ 2 GidrotehproektLtd., Toreza pr. 44, St. Petersburg, Russia \\ 3 St. Petersburg State University, Universitetskaya nab 7-9, St. Petersburg, Russia \\ 4 Hydrograph model Research Group, St. Petersburg, Russia \\ 5 National Research Institute of Science and Technology for Environment and Agriculture (Irstea), Hydrology Research \\ Unit Aix-en-Provence, 3275 route Cézanne CS 40061, 13182 Aix-en-Provence, France
}

\begin{abstract}
Data analysis and amodelling approach were used to detect the changes in hydrological regime in the Rimbaud watershed (France) after the fire in 1990. It was revealed that the increase of peak discharges was only observed during three years after the fire in the wet period of the year, at an hourly time scale. The Hydrograph model was applied for continuous runoff simulations at an hourly time step for the period 19672004. The parameters assessed for pre-fire conditions and used without change for the post-fire period satisfactorily fit the whole period of simulations with mean Nash-Sutcliffe efficiency 0.52 . The set of model parameters representing the post-fire conditions of changing environment was developed. Based on newly estimated parameters, the efficiency of simulations of selected outstanding flood peaks was improved However, overall model representation for the post-fire period (1990-1992) has declined. It is concluded that discernible fire impact is only localized on separate floods events and that it has a nonlinear character.
\end{abstract}

Key words flood; modelling; fire; non-stationary; Hydrograph model

\section{INTRODUCTION}

Reported impacts of forest fires on hydrological systems usually include reduced infiltration and evapotranspiration rates and increased overland flow (Shakesby and Doerr 2006). Decreased evaporation and interception are usually related to depletion of vegetation cover (Neary et al.2005). Changing infiltration and overland flow formation are associated with physical properties of the soil.

Although there are many experimental and analytical studies investigating vegetation and soil properties reaction and transformation after fire (Rosso et al. 2007, González-Pelayo et al. 2010, Soulis et al. 2012), their results often do not agree well with each other and could hardly be transferred to other (larger) scales. Sufficient modelling approaches taking into account physical landscape properties and its post-fire changes are not still developed (Hinzman et al. 2003).

The aim of the study presented here is to quantify the hydrological response of the small Mediterranean Rimbaud watershed to wild fire and investigate the ability of a process-based hydrological model to cope with non-stationary post-fire conditions.

\section{STUDY AREA}

The Rimbaud watershed is located in the Maures massif, Var Department, France, $15 \mathrm{~km}$ away from the Mediterranean Sea. The watershed area is $1.46 \mathrm{~km}^{2}$, elevation ranges from 470 to $620 \mathrm{~m}$. The discharge and meteorological measurements were carried out from 1967 to 2006 . The data are available in daily and hourly time steps.

Intense autumn rains and summer droughts are typical climatic features of the Rimbaud watershed. Mean annual precipitation and flow depth for 1967-2006 is $1200 \mathrm{~mm}$ and $700 \mathrm{~mm}$, respectively. Predominant vegetation is shrubby maquis and a degraded forest of cork oak, chestnut and maritime pines (Lavabre et al. 1993). The basin is geologically homogenous, underlain by slightly altered gneiss (Cosandey et al. 2005). Thin sandy soil of ranker type covers the watershed. In August 1990, 82\% of the watershed was burned (Vine et al. 1996). 


\section{HYDROGRAPH MODEL}

The process-based hydrological model Hydrograph with observable parameters (Vinogradov et al. 2011, Semenova et al. 2013) was applied in the study. It is a distributed model of runoff generation processes describing all essential components of the land hydrological cycle including precipitation interception; thermo-dynamic modelling of snow accumulation and melt; representation of soil and vegetation cover and evapotranspiration; surface flow and infiltration; soil water dynamics; heat dynamics and phase change in soil layers; subsurface flow, hillslope and channel flow and routing.

The main model parameters directly relate to vegetation and soil properties. Process-based algorithms supported by observable parameters allow avoiding of a heavy calibration procedure.

The model concepts and approaches were verified at numerous basins in Russia, USA, Europe and Canada (Lebedeva and Semenova 2011, Vinogradov et al. 2011, Semenova et al. 2013).

In the reported study the Hydrograph model was applied for runoff simulation in pre- and post-fire periods to detect the changes in hydrological regime of the Rimbaud watershed. Further, modelling experiments were carried out aimed at investigating the model's ability to simulate postfire flow, taking into account vegetation and soil properties changes.

\section{RESULTS}

\section{Analysis of runoff and rainfall time series on daily and hourly time step}

The presented study includes the analysis of daily and hourly rainfall and runoff data. The data of 134 daily and 190 hourly flood events with precedent rainfall higher than $20 \mathrm{~mm}$ during the wet season (September-December) from 1967 to 2006 were investigated. The years 1967-1989 and 1993-2006 were treated as the reference periods and 1990-1992 as the post-fire period. The decision to concentrate on peak flood analysis mainly was supported by the studies of Cosandey et al. (2005) and Lavabre and Martin (1997) who found that the response to heavy rain is particularly violent after fire, while longer-lasting, gentler frontal rainfall causes very much the same flood response both before and after forest fire.

The analysis has shown that the fast response of the small Rimbaud watershed to rainfall makes it impossible to distinguish any fire impact on daily peak floods (Fig. 1(a)). An apparent increase of hourly peak discharges can be detected for the autumn-winter (September-December) period during three years after the fire (1990-1992), comparative to the reference period (Fig. 1(b)). The data show that median peak floods increased from $0.77 \mathrm{~m}^{3} / \mathrm{s}$ in 1967-1989 (112 events) up to $1.26 \mathrm{~m}^{3} / \mathrm{s}$ in 1990-1992 (14 events) and then decreased to $0.59 \mathrm{~m}^{3} / \mathrm{s}$ in 1993-2006 (64 events). Mean rainfall of $>20 \mathrm{~mm}$ for the post-fire period slightly decreased in the post-fire period (40 mm compared with 53.5 and $44.8 \mathrm{~mm}$ ). It agrees with the results found by Lavabre et al. (1993) that 30\% runoff increase in the Rimbaud watershed is mainly observed during high water days. Also Lavabre and Martin (1997) reported about extreme reactivity of streams to precipitation after fire when rising flood stages often lasted no more than five minutes, and recession was also very rapid.

\section{Hydrological modelling on daily and hourly time step with pre-fire model parameters}

The Hydrograph model was applied to the Rimbaud watershed for the continuous period 19682004 on daily and hourly time steps. Initially the parameters were adjusted for a pre-fire period and used to simulate a full period of 1968-2004 to assess possible changes in hydrological regime by the model detection method (Seibert et al. 2010). The simulations were conducted for the Rimbaud watershed in a lumped way because of absence of any data about spatial distribution of land cover and meteorological input for the $1.46 \mathrm{~km}^{2}$ watershed.

According to Cosandey et al. (2005) who reported the soil depth to be no deeper than $30 \mathrm{~cm}$, the soil profile was divided into three computational soil layers of $10 \mathrm{~cm}$ each. The values of infiltration coefficient for the pre-fire period were assessed as $3.75 \mathrm{~mm} \mathrm{~min}^{-1}$ for the upper soil layer and $0.75 \mathrm{~mm} \mathrm{~min}^{-1}$ for the second and third layers based on a soil description by Cosandey et 
al. (2005) and manual adjustment of severe flood events for the period 1968-1989. Maximum water holding capacity was defined as $0.3 \mathrm{~m}^{3} \mathrm{~m}^{-3}$ for all three soil layers. Vegetation parameters were estimated according to dominant vegetation types, such as shrubby maquis and degraded forest of cork oak, chestnut and maritime pines (Lavabre et al. 1993). Seasonal shadow fraction by vegetation was assumed to be $0.3 \mathrm{~m}^{2} \mathrm{~m}^{-2}$, interception storage capacity $2 \mathrm{~mm}$, landscape albedo 0.2 and coefficient of evaporation $0.3 \times 10^{-8} \mathrm{hPa}$ s. Only general information was available about the watershed geology. The underground flow was assumed to be produced by four storages: the underground runoff elements with characteristic outflow time from one day to one month (Vinogradov et al. 2011). The share of contribution of each layer to total underground flow decreases from 0.4 to 0.1 from upper (fastest) to lower (slowest).

(a)

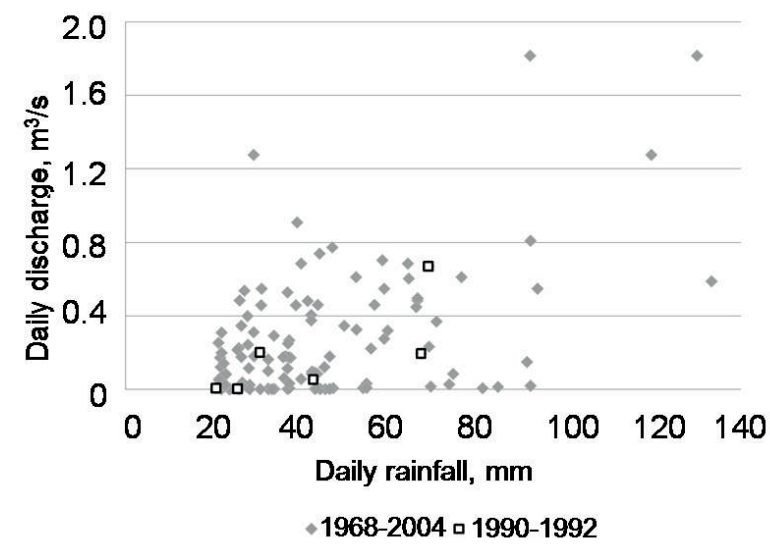

(b)

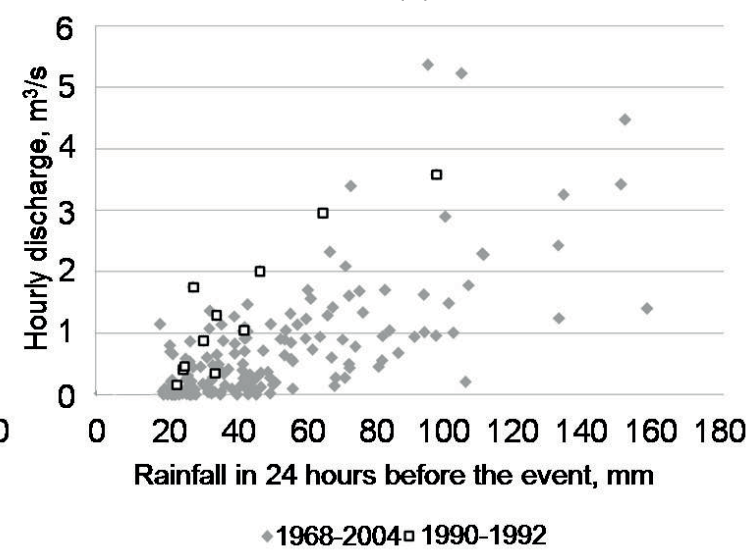

Fig. 1 The relationship between peak flood discharge and precipitation on daily (a) and hourly time step (b) throughout the autumn-winter period (Sep., Oct., Nov. and Dec.).

(a)
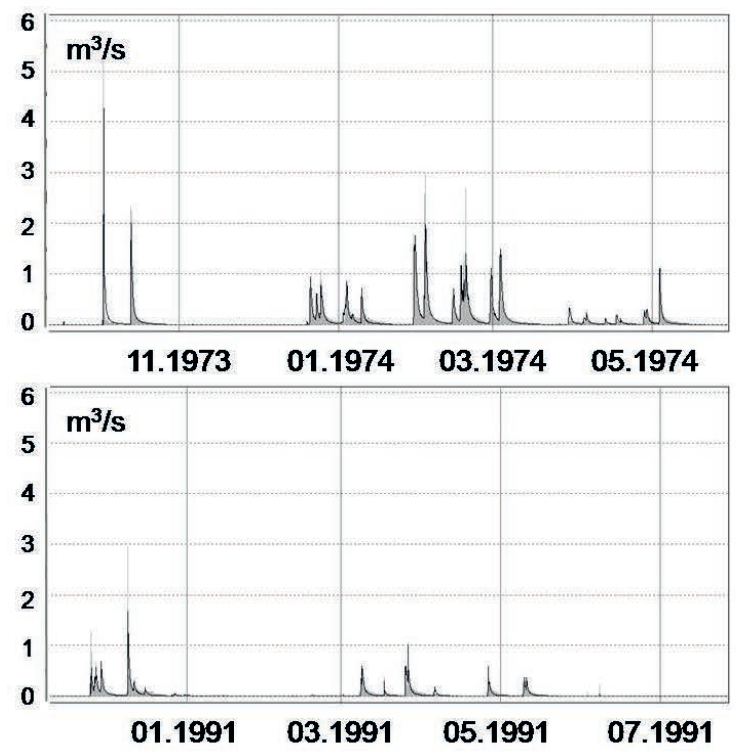

(b)
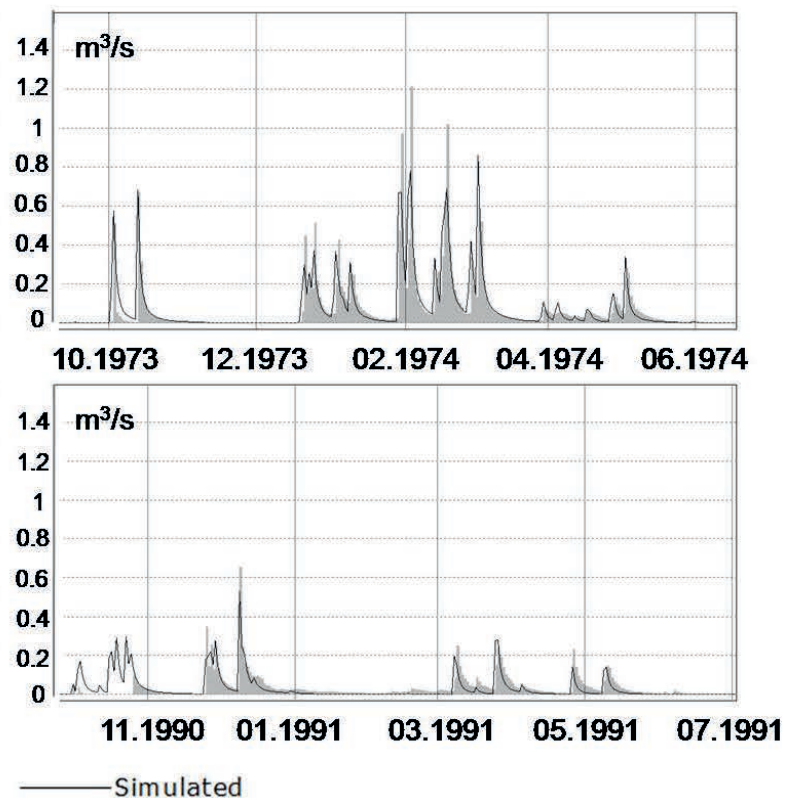

Fig. 2 Simulated and observed hydrographs for pre- and post-fire periods simulated on daily (a) and hourly (b) time step.

Figure 2 shows simulated and observed hydrographs for 1973-1974 (pre-fire) and 1990-1991 (post-fire) periods on an hourly (b) and daily (a) time step. Modelling results have satisfactory agreement with observed values on both daily and hourly time steps (Fig. 2). Annually averaged 
Nash-Sutcliffe efficiency (NS) of hourly simulations for 1968-2004 is 0.52 , varying from negative values to 0.84 . Annually-averaged NS for daily simulations is 0.76 , changing from negative values to 0.91 . The NS has a strong positive correlation with annual rainfall amount. One of the possible reasons is the discontinuous character of channel flow throughout the year; it is quite difficult to accurately simulate the transition between flow presence and absence in the recession limb of hydrographs.

As shown in Fig. 3 the simulations have a tendency to slight underestimation of hourly high flood peaks greater than $2 \mathrm{~m}^{3} / \mathrm{s}$ and overestimation of floods lower than $2 \mathrm{~m}^{3} / \mathrm{s}$.

Modelling results do not detect any significant changes after the fire on a regular basis. Annually-averaged NS assessed for hourly simulations is 0.56 for 1968-1987, 0.45 for 1990 1992, and 0.58 for 1990-1994. The exceptions are several peak floods during 1990-1992 that were considerably underestimated by the simulations and are discussed in detail in the next section.

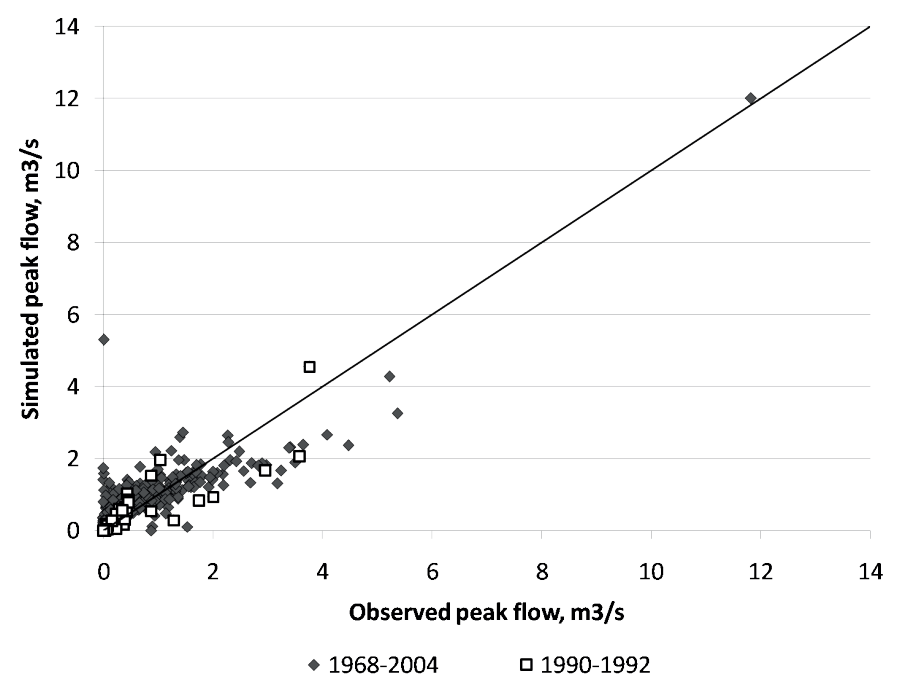

Fig. 3 Comparison between observed and simulated hourly peak floods for 24-hour rainfall events $>20 \mathrm{~mm}$ for pre-and post-fire periods.

\section{Modelling experiments}

To investigate the Hydrograph model's ability of coping with non-stationary post-fire conditions it was applied to the 1990-1992 period with new landscape parameters. The parameters were reestimated according to the changing watershed environment for three years after the fire. Vine et al. (1996) reported that in August 1990 82\% of the watershed was burned. As a result of the fire most of the trees were destroyed. Bare soil increased up to $90 \%$ immediately after the fire and gradually decreased to $25 \%$ in the next four years. Herbs and shrubs cover developed six months after the fire.

To account for new conditions, vegetation parameters were changed in the following way: seasonal shadow fraction by vegetation and interception storage capacity were nullified, the value of landscape albedo was reduced to 0.1 and the coefficient of evaporation to $0.17 \times 10^{-8} \mathrm{hPa}$. The change of the evaporation coefficient is consistent with the conclusions drawn by Lavabre et al. (1993), about $40 \%$ reduction of annual water losses after the fire.

DeBano (2000) found that during a wildfire, organic compounds vaporised in burning vegetation move through the soil and form a water-repellent, or hydrophobic soil layer. Many studies reported a considerable decline of infiltration rates due to fire (Soulis et al. 2012). At the same time it was shown that on Mediterranean hillslopes soil properties are not uniformly distributed (Bergkam et al. 1996) and many of them vary in patches related to micro-topography and vegetation (Gimeno-García et al. 2001, Bochet et al. 2006). Soulis et al. (2012) reported high variability of measured infiltration coefficients after the fire in a small basin in Greece. Based on information from the literature and modelling experiments with different infiltration rates, the 
coefficient of infiltration was assumed to be $1.5 \mathrm{~mm} \mathrm{~min}^{-1}$ for the upper soil layer and $0.75 \mathrm{~mm}$ $\mathrm{min}^{-1}$ for the middle and lower ones for 1990-1992 (against $3.75 \mathrm{~mm} \mathrm{~min}^{-1}$ for the upper soil layer and $0.75 \mathrm{~mm} \mathrm{~min}^{-1}$ for the second and third layers for the pre-fire period). According to reported increased variability of soil properties after the fire the variation coefficient of infiltration equal to 0.7 was introduced into the simulations.

The comparison of observed and simulated hydrographs with pre-fire and post-fire parameters for selected flood events is presented in Fig. 4. Four outstanding events were chosen for the investigation: (a) precipitation (P total) $=34.6 \mathrm{~mm}$, discharge $\left(\mathrm{Q}_{\mathrm{h}} \max \right)=1.29 \mathrm{~m}^{3} / \mathrm{s}$, (b) $\mathrm{P}$ total $=$ $65.1 \mathrm{~mm}, \mathrm{Q}_{\mathrm{h}} \max =2.96 \mathrm{~m}^{3} / \mathrm{s}$ on the 9 December 1990, (c) $\mathrm{P}$ total $=28 \mathrm{~mm}, \mathrm{Q}_{\mathrm{h}} \max =1.7 \mathrm{~m}^{3} / \mathrm{s}$ on the 14 October 1991, (d) P total $=47.1 \mathrm{~mm}, \mathrm{Q}_{\mathrm{h}} \max =2 \mathrm{~m}^{3} / \mathrm{s}$ on the 1 November 1992. They have shown a $25-50 \%$ increase in peak discharge compared to the events caused by the same rainfall in the reference period. It agrees with the results by Lavabre et al. (1993) who found a 30\% increase in runoff in the Rimbaud watershed, mainly concentrated in the high water days.

A newly developed set of model parameters improved the efficiency of the simulation for the selected peak floods to a certain extent. However, overall model representation for 1990-1992 has declined. One may conclude that fire impact is localized on separate events only. Such an assumption is consistent with the findings of Lavabre et al. (1993) about runoff increase in the Rimbaud watershed after the fire, mainly during the high water days. Soulis et al. (2012) when investigating such behaviour found that fire impact on soil infiltration rate only appeared after the effect of the first rainfall event. Significantly decreased infiltration values and extraordinary high peak runoff values observed after first autumn rainfalls could be attributed to the formation of a crust on the soil surface under the effect of the forest fires and the rainfall.
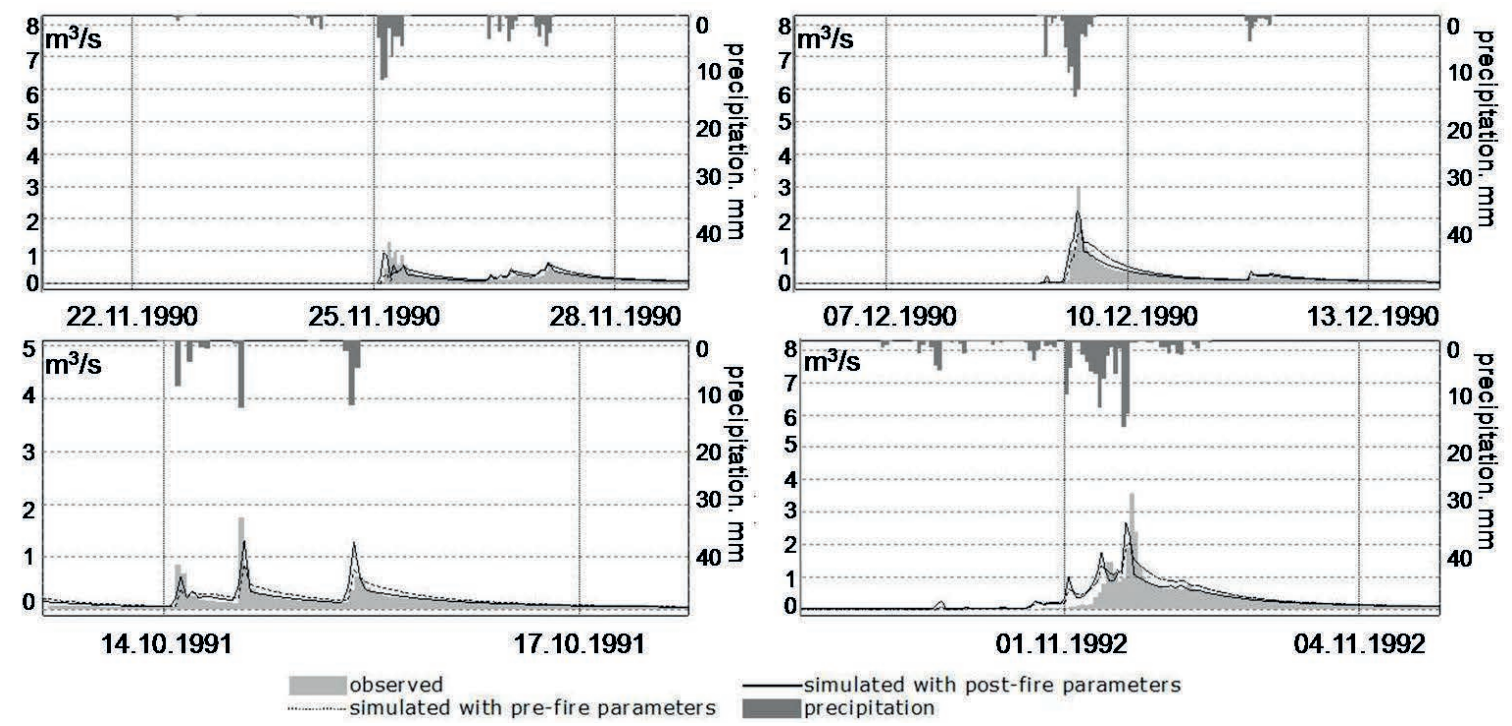

Fig. 4 Observed and simulated with pre- and post-fire parameters hydrographs of selected peak floods 1990-1992.

\section{CONCLUSION}

No significant changes in hydrological regime of the Rimbaud watershed after the fire in 1990 are detected on a daily temporal scale. Data analysis on hourly time step revealed a general increase of peak discharges during three years after the fire (1990-1992) compared to the reference period (1967-2004), but only in September-December (wet) period.

The Hydrograph model was applied for continuous runoff simulations at hourly time steps for the period 1967-2004. The parameters assessed for pre-fire conditions and used without change for post-fire period satisfactorily fit the whole period of simulations. Mean Nash-Sutcliffe efficiency estimated for simulations is 0.56 for 1968-1987, and 0.58 for 1990-1994. The 
exceptions are several peak floods during a wet period of 1990-1992 that were considerably underestimated by the simulations.

A set of the model parameters representing the post-fire conditions of changing environment was developed. Infiltration coefficient turned out to be the most sensitive parameter to the results of simulations. Based on newly estimated parameters, the efficiency of simulations of selected outstanding flood peaks was improved. However, overall model representation for 1990-1992 declined. We have concluded that discernible fire impact is localized on separate floods events only and has nonlinear character. At present the Hydrograph model is not able to represent the watershed behaviour in the post-fire period and further investigations are required.

Acknowledgements The authors acknowledge Guillaume Thirel from National Research Institute of Science and Technology for Environment and Agriculture (Irstea) for his valuable clarifications of all data issues. The reported study was partially supported by RFBR, research projects no. 1405-00665 and 14-05-31194.

\section{REFERENCES}

Bergkam, G., Cammeraat, L. H. and Martínez-Fernández, J. (1996) Water movement and vegetation patterns on shrubland and an abandoned field in two desertification-threatened areas in Spain. Earth Surface Processes and Landforms 21, 1073-1090.

Bochet, E., Poesen, J. and Rubio, J. L. (2006) Runoff and soil loss under individual plants of a semi-arid Mediterranean shrubland: influence of plant morphology and rainfall intensity. Earth Surface Processes and Landforms 31, $536-549$.

Cosandey, C., et al. (2005) The hydrological impact of the Mediterranean forest: A review of French research. Journal of Hydrology 301, 1-15, 235-249.

DeBano, L. (2000) The role of fire and soil heating on water repellency in wildland environments: a review. Journal of Hydrology 231-232, 195-206.

Gimeno-García, E., Andreu, V., and Rubio, J. L. (2001) Influence of Mediterranean shrub species on soil chemical properties in typical Mediterranean environment. Commun. Soil Sci. Plant Anal. 32(11-12), 1885-1898.

González-Pelayo, O., et al. (2010) Effects of fire and vegetation cover on hydrological characteristics of a Mediterranean shrubland soil. Hydrol. Processes 24, 1504-1513. doi: 10.1002/hyp.7612.

Hinzman, L. D., et al. (2003) FROSTFIRE: an experimental approach to predicting the climate feedbacks from the changing boreal fire regime. Journal of Geophysical Research, 108: article D18153, doi: 10.1029/2001JD000415.

Lavabre, J. and Martin, C., (1997) Impact d'un incendie de forêt sur l'hydrologie et l'érosion hydrique d'un petit bassin versant méditerranéan. In: Human Impact on Erosion and Sedimentation (ed. by D. E.Walling and J. L. Probst). Proceedings Proc. of Rabat Symposium S6, April 1997. IAHS Publ. 245, 39-47. IAHS Press, Wallingford, UK.

Lavabre, J., Sempere, D., and Cernesson, F. (1993) Changes in the hydrological response of a small Mediterranean basin a year after a wildfire. J. Hydrol. 142, 273-299.

Lebedeva, L. and Semenova, O. (2011) Evaluation of climate change impact on soil and snow processes in small watersheds of European part of Russia using various scenarios of climate. Die Bodenkultur - Journal for Land Management, Food and Environment. 62, 77-82.

Neary D. G., Ryan K. C., and DeBano L. F. (eds) (2005) (revised 2008) Wildland fire in ecosystems: effects of fire on soils and water. Gen. Tech. Rep. RMRS-GTR-42-vol.4. Ogden, UT: US Department of Agriculture, Forest Service, Rocky Mountain Research Station. 250 p.

Rosso, R., Rulli, M. C. and Bocchiola, D. (2007) Transient catchment hydrology after wildfires in a Mediterranean basin: runoff, sediment and woody debris. Hydrol. Earth Syst. Sci. 11, 125-140, doi:10.5194/hess-11-125-2007.

Seibert, J., McDonnell, J. J. and Woodsmith, R. D. (2010) Effects of wildfire on catchment runoff response: a modeling approach to detect changes in snow-dominated forested catchments. Hydrology Research 41(5), 378-390.

Semenova, O., Lebedeva, L. and Vinogradov, Yu (2013) Simulation of subsurface heat and water dynamics, and runoff generation in mountainous permafrost conditions, in the Upper Kolyma River basin, Russia. Hydrogeology Journal 21(1), 107-119 DOI:10.1007/s10040-012-0936-1.

Shakesby, R. A. and Doerr, S. H. (2006) Wildfire as a hydrological and geomorphological agent. Earth Science Reviews 74, 269-307.

Soulis, K. X., Dercas, N., and Valiantzas, J. D. (2012) Wildfires impact on hydrological response - the case of Lykorrema experimental watershed. Global NEST Journal 14(3), 303-310.

Vine, P., et al.et al. (1996) Remote sensing and vegetation recovery mapping after a forest fire. EARSel. Advances in Remote Sensing 4, No.4, 155-158

Vinogradov, Yu, Semenova, O., and Vinogradova T. (2011) An approach to the scaling problem in hydrological modelling: the deterministic modelling hydrological system. Hydrol. Processes 25, 1055-1073 doi: 10.1002/hyp.7901. 